\title{
Diversity and Antibacterial Screening of Actinomycetes from Javadi Hill Forest Soil, Tamilnadu, India
}

\author{
Sakthi Velayudham ${ }^{1}$, Kasi Murugan ${ }^{2, *}$ \\ ${ }^{1}$ Research and Development Center, Bharathiyar University, Coimbatore, 46, Tamilnadu, India \\ ${ }^{2}$ Department of Botany and Microbiology, College of Science, King Saud University, P.O.Box 2455, Riyadh, 11451, Saudi Arabia
}

\begin{abstract}
Actinomycetes from diverse environments are known to produce novel antibacterial and antifungal substances. Herein we report isolation of antibiotic producing actinomycetes from forest soil of ancient human inhabited Javadi hill, Tamilnadu, India, an environment that is under explored. Thirty six isolates were obtained from five soil samples using nalidixic acid and nystatin supplemented starch casein agar and actinomycete isolation agar medium. These colonies NLO were characterized based on their mycelium structure, colour and arrangement of spores on the mycelium. Further they were evaluated for their antimicrobial activity against a range of pathogenic resistant bacteria including Escherichia coli (MTCC 739), Bacillus cereus (MTCC 1272), Staphylococcus aureus (MTCC 1144), Pseudomonas aeruginosa (MTCC 1688), Proteus mirabilis (MTCC 1425) and Klebsiella pneumonia (MTCC 109) adopting agar plug method and confirmed by cross streak method.
\end{abstract}

Keywords Actinomycetes, antibacterial activity, antagonistic activity, pathogens

\section{Introduction}

Microorganisms are virtually an unlimited source of novel substances with many therapeutic applications and consequently their secondary metabolite screening for pharmaceutically significant novel antibiotic and non - antibiotic compounds and drug lead molecules has assumed greater attention in recent times. Many soil-inhabiting bacteria are known to produce secondary metabolites that can suppress microorganisms competing for the same resources[1].

Actinomycetes are the most commonly distributed microbes in nature which largely inhabits the soil environment[2]. They form the dominant and significant group among the soil microbial community and comprise about $50 \%$ of the uncultivable soil microbes. They play a major role in the recycling of organic matter, production of novel pharmaceuticals, nutritional materials, cosmetics, enzymes, antitumor agents, enzyme inhibitors, immune modulators, and vitamins. Numerous naturally occurring antibiotics have been discovered from actinomycetes ever since the discovery of Selman Waksman's streptomycin from this group and several studies signify their noteworthy antibiotic production[3]. Further, about two thirds of known significant naturally occurring antibiotics are actinomycete derived one and are the prominent candidates receiving number of product and processes related patents.

* Corresponding author:

murutan@gmail.com (Kasi Murugan)

Published online at http://journal.sapub.org/microbiology

Copyright (C) 2012 Scientific \& Academic Publishing. All Rights Reserved
Though ecological studies on soil actinomycetes from various habitats including grasslands, beach sands, underground caves, rice-paddies, orchards and sub-glacial ice of Antarctica were reported, only few reports are available on forest soil actinomycete communities[4]. These ubiquitous organisms are deemed to have a preference over the soil constituents such as humus, litter, dung and even rock surfaces. In fact actinomycetes are the dominant microflora showing viable counts reaching $10^{6}$ per gram of dry weight soil in relatively dry, humic, and calcareous soils,[5].

The Eastern Ghats is a discontinuous range of mountains along the east coast of India, located between $10^{\circ} 05^{\prime}$ and $22^{\circ}$ $30^{\prime} \mathrm{N}$ latitude and $76^{\circ} 23^{\prime}$ and $86^{\circ} 50^{\prime} \mathrm{E}$ longitudes in north east to southwest strike, which is broken and comprises many viz. Shevaroys, Kalrayan, Chitteri, Kollimalai, Pachchimalai hills of Tamilnadu. Very little information is available on the actinomycetes population of these hills including those from Kollimalai[6] and Pachamalai[7].

Wealth of information/ knowledge is available on the early inhabitants of Javadi hills, a place inhabited by human being even during Stone Age. Claims for supporting this are available in the form of 4000 years old Stone Age tribal caves. There are traces of evidence depicting the presence of Chitra Kullers before the invasion of present day outsiders. The rock houses still exist at Chepli above Pattaraikadu giving an affirmation that they might be kullers or the early tribes who lived as hunters. The glory of Javadi hills was prized even in the Patthu pattu, one of the earliest classical language Tamil literatures.

The Javadi Hills, the largest of Eastern Ghats forest consists of dray mixed deciduous to thorny shrubs with occa- 
sional patches of dray ever green growth. The maximum temperature go up to $44.4{ }^{\circ} \mathrm{C}$ during the summer month May and minimum temperature falls to $11.7^{0} \mathrm{C}$ during the winter month January. The average rain fall is about $886 \mathrm{~mm}$. Amirthi forest is situated under the Javvadu/Javadi Hills of Tellai across Amirthi River contains a wide variety of flora and fauna. The soil is highly rich in organic matter and suitable for the growth of microorganisms[8].

Although there are a number of reports on distribution and traditional uses of medicinal plants from these early human inhabitated areas are readily available, data on their microbial resources are scarce, imprecise, and not well documented. Due to uniqueness, large geographic variation, different soil types and their contents of this forest, it is quite likely that there is vast distribution of antibiotic producing actinomycetes in this environment. The present study was carried out to screen the most assured antimicrobial compounds producing actinomycetes from these unexplored soils for possible harnessing of potential antibiotics from the actinomycetes towards combating highly resistant pathogenic bacteria.

\section{Materials and Methods}

\subsection{Sampling Area and Sample Collection}

The Javadi Hills, the largest of Eastern Ghats are located in Vellore district (Tamilnadu, India) at an altitude of $300-1000 \mathrm{~m}$ above sea level (longitude $78^{\circ} 40^{\prime} \mathrm{E}$; latitude $12^{\circ}$ $40^{\prime} \mathrm{N}$ ), in North to South direction, covering a distance of 80 $\mathrm{km}$ in width and $32 \mathrm{~km}$ in length. Its average height is about $214 \mathrm{~m}$, bisected into eastern and western sections by the Cheyyar and Agaram rivers. The centre of the Javadi hills consists of extensive undulating plateau with large valleys ranging from 500-800 metres. Soil samples were collected from this hill at 10-15 cm depth of the soil[9], air-dried for 1 week[10], crushed, and sieved. The sieved soils were then used for isolation of actinomycete.

\subsection{Isolation of Actinomycetes Isolates}

The actinomycetes from crushed and sieved soil samples were isolated as described previously[11] employing serial dilution and spread plate technique. One gram of soil sample was transferred into $9 \mathrm{ml}$ of sterile double distilled water $\left(10^{1}\right)$ and serially diluted up to $10^{-5}$ dilutions using each $9 \mathrm{ml}$ of sterile double distilled water blanks. Hundred microliter of diluted soil sample from $10^{-3}, 10^{-4}$ and $10^{-5}$ dilutions was spreaded on starch casein agar[12] plates supplemented with nalidixic acid $(20 \mu \mathrm{g} / \mathrm{ml})$ and nystatin $(100 \mu \mathrm{g} / \mathrm{ml})$ as well as actinomycete isolation agar (M490, HiMedia, Mumbai, India). Plating was done in triplicate and all the plates were incubated at $28^{\circ} \mathrm{C}$ for one week. The individual colonies were selected based on morphology and purified by inoculation onto ISP-2 (International Streptomyces Project) agar plates which were incubated for $7-14$ days at $28^{\circ} \mathrm{C}$. Morphologically distinct colonies were selected for further studies.

\subsection{Microorganisms Used}

The bacterial strains of Escherichia coli (MTCC 739), Bacillus cereus (MTCC 1272), Staphylococcus aureus (MTCC 1144), Pseudomonas aeruginosa (MTCC 1688), Proteus mirabilis (MTCC 1425) Klebsiella pneumonia (MTCC 109) as well as Candida albicans obtained from microbial type culture collection (MTTC) Chandigarh, India were used in this study.

\subsection{Determination of Bacterial Antagonistic Activity}

Antagonistic activities of the selected isolates were tested by adopting agar plug method[13]. The isolates were inoculated onto ISP2 agar plates and were allowed to grow restricted towards one end of the plate for 10 days. Later 5 $\mathrm{mm}$ diameter core agar plug were removed from the grown cultures and the surface growth on agar was removed with sterile knife to allow remaining of only the diffused microbial metabolites in the agar plugs. The agar plugs were placed onto the nutrient agar plate which was previously swabbed with the test pathogens. All the plates were then incubated at $37^{\circ} \mathrm{C}$ for $24 \mathrm{~h}$. After incubation, antimicrobial activity indicated by the formation of an inhibition zone surrounding the agar plug was measured. The absence of an inhibition zone around the plugs indicated a negative result. The observed growth inhibitory activities of the isolates were further confirmed by cross streak test. The isolates showing significant inhibitory activities were inoculated on modified nutrient glucose agar (MNGA) plates by single streak in the center and incubated at $28^{\circ} \mathrm{C}$ for four days. The previously used test pathogenic organisms were inoculated perpendicular to the actinomycetes growth and incubated at $37^{\circ} \mathrm{C}$ for $24 \mathrm{~h}$. The antagonistic activities of the isolate were confirmed by their growth inhibition. Isolates showing significant inhibitory activity against at least two pathogenic test organisms were further selected for secondary screening.

\subsection{Determination of Bioactive Compound production and Their Inhibitory Activity}

The bioactive substance producing ability of the isolates that showed antagonistic activity was determined by a method described by Mohanraj et al.[14]. Briefly, the selected bacterial antagonistic isolates were grown in submerged fermentation condition by adopting shake flask method. Initially $10 \%$ of culture inoculum was transferred into each $100 \mathrm{ml}$ of ISP2 broth and incubated in a rotary shaker with $95 \mathrm{rpm}$ at $28^{\circ} \mathrm{C}$ for 7 days. The cell free supernatant was obtained and $100 \mu \mathrm{l}$ was poured into $5 \mathrm{~mm}$ well made in nutrient agar (NA) plates. The NA plates were previously inoculated with test organism cultures as described. After incubation the diameter of the zone of inhibition was measured in millimeter and recorded. The isolates were designated as BKM (Bheemakulam), KUR (Kavalur ), PMR (Palamarathur), VPR (Veerappanur) as well as JMR (Jamunamathur) according to the place of collection and 
preserved in $15 \%$ glycerol $(\mathrm{v} / \mathrm{v})$ slants at $-20^{\circ} \mathrm{C}$.

\section{Results and Discussion}

Antibiotics are an indispensable part of modern medicine. The emergence of antibiotic-resistance among pathogenic bacteria is apparently certain, and results, within a few decades, in decreased efficacy and withdrawal of the antibiotic from general practice. Hence for the continuance of modern medicine in its present form, novel families of antibiotics must be available in the market at regular intervals[15]. Many important bioactive compounds of high commercial value were obtained from actinomycetes and the screening is being continued for deriving new bioactive compounds especially novel antibiotics active against resistant organisms. This endeavour was undertaken with an objective of identifying culturable new actinomycetes having novel anti-bacterial activity against the resistant pathogenic bacteria from the virgin soils of Javadi hills.

Table 1. Morphology and colour of aerial mycelium of Actinomycetes isolates

\begin{tabular}{|c|c|c|c|c|}
\hline S.No & Isolates Name & Colour of colony & Colony texture & Morphology of hyphae \\
\hline 1 & BKM -1 & Yellow & Fine substrate mycelium & long fragmented \\
\hline 2 & BKM -2 & Grey & Powdery colony & Extended spiral \\
\hline 3 & BKM -3 & Brown & Waxy colony & long fragmented \\
\hline 4 & BKM -4 & Grey-white & Powdery colony & Extended spiral \\
\hline 5 & BKM -5 & Grey & Powdery colony & Straight Un fragmented \\
\hline 6 & BKM -6 & Grey & Powdery colony & Extended spiral \\
\hline 7 & BKM -7 & Grey-white & Powdery colony & Extended spiral \\
\hline 8 & KUR-8 & Yellow & Fine substrate mycelium & long fragmented \\
\hline 9 & KUR -9 & Grey & Powdery colony & Straight -Un fragmented \\
\hline 10 & KUR -10 & Reddish brown & Fine substrate mycelium & Straight -Un fragmented \\
\hline 11 & KUR -11 & Grey & Powdery colony & Extended spiral \\
\hline 12 & KUR -12 & Yellow brown & Waxy colony & Straight looped end \\
\hline 13 & PMR-13 & Reddish brown & Fine substrate mycelium & Straight -Un fragmented \\
\hline 14 & PMR -14 & Orange & Fine substrate mycelium & long fragmented \\
\hline 15 & PMR -15 & Red & Fine substrate mycelium & Extended spiral \\
\hline 16 & PMR -16 & Grey & Powdery colony & Extended spiral \\
\hline 17 & PMR -17 & Yellow & Waxy colony & long fragmented \\
\hline 18 & PMR -18 & Grey-white & Powdery colony & Extended spiral \\
\hline 19 & PMR -19 & Grey & Powdery colony & Extended spiral \\
\hline 20 & PMR -20 & Grey & Powdery colony & Extended spiral \\
\hline 21 & PMR -21 & Reddish brown & Fine substrate mycelium & Straight -Un fragmented \\
\hline 22 & PMR -22 & Grey yellow & Powdery colony & Straight looped end \\
\hline 23 & VPR-23 & Grey & Powdery colony & Straight -Un fragmented \\
\hline 24 & VPR -24 & Yellow & Fine substrate mycelium & long fragmented \\
\hline 25 & VPR -25 & Yellow & Fine substrate mycelium & long fragmented \\
\hline 26 & VPR -26 & Reddish brown & Fine substrate mycelium & Straight -Un fragmented \\
\hline 27 & VPR -27 & Orange & Fine substrate mycelium & long fragmented \\
\hline 28 & VPR -28 & Grey violet & Powdery colony & Extended spiral \\
\hline 29 & VPR -29 & Grey & Powdery colony & Extended spiral \\
\hline 30 & VPR -30 & Red & Fine substrate mycelium & Extended spiral \\
\hline 31 & JMR-31 & Yellow & Fine substrate mycelium & long fragmented \\
\hline 32 & JMR -32 & Reddish brown & Fine substrate mycelium & Straight -Un fragmented \\
\hline 33 & JMR -33 & Grey pink & Powdery colony & Straight -Un fragmented \\
\hline 34 & JMR 34 & Grey-white & Powdery colony & Extended spiral \\
\hline 35 & JMR 35 & Brown & Fine substrate mycelium & long fragmented \\
\hline 36 & JMR 36 & Grey & Powdery colony & Extended spiral \\
\hline
\end{tabular}




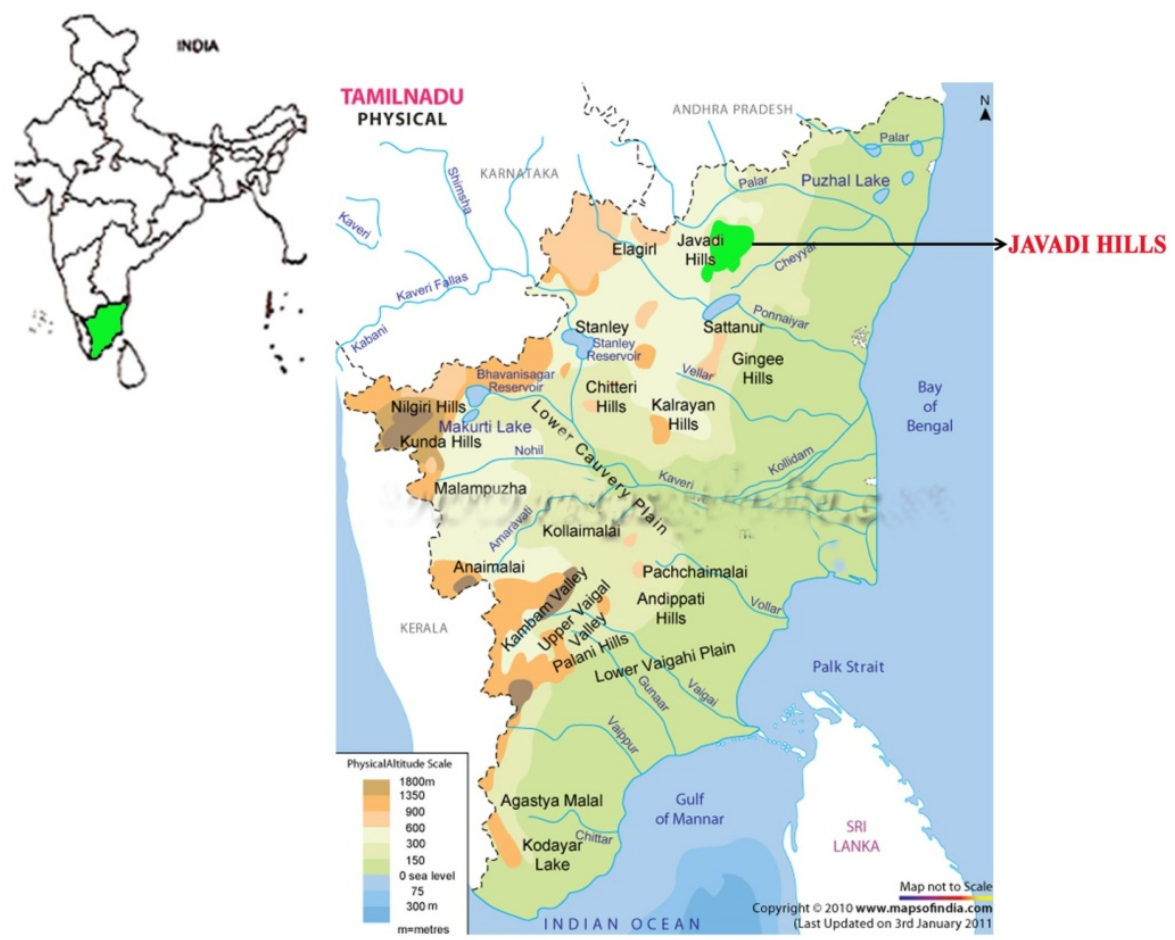

Figure 1. Schematic map showing the location of Javadi hills, Tamilnadu, India(Courtesy:www.mapsof India)

Table 2. Screening for antagonistic activity

\begin{tabular}{|c|c|c|c|c|c|c|c|c|}
\hline S.No. & Isolates & EC & BS & SA & PA & PM & KP & $\mathrm{CA}$ \\
\hline 1 & BKM-1 & 22 & 0 & 0 & 11 & 0 & 18 & 13 \\
\hline 2 & BKM-2 & 0 & 13 & 15 & 0 & 0 & 0 & 0 \\
\hline 3 & BKM-3 & 17 & 0 & 13 & 12 & 10 & 11 & 0 \\
\hline 4 & BKM-4 & 24 & 16 & 18 & 20 & 14 & 25 & 0 \\
\hline 5 & BKM-5 & 0 & 15 & 15 & 0 & 0 & 0 & 12 \\
\hline 6 & BKM-6 & 0 & 14 & 11 & 0 & 0 & 0 & 11 \\
\hline 7 & BKM-7 & 15 & 0 & 0 & 14 & 16 & 17 & 0 \\
\hline 8 & KUR-8 & 18 & 0 & 0 & 13 & 0 & 22 & 12 \\
\hline 9 & KUR-9 & 0 & 16 & 18 & 0 & 0 & 0 & 0 \\
\hline 10 & KUR-10 & 8 & 11 & 9 & 11 & 12 & 10 & 0 \\
\hline 11 & KUR-11 & 0 & 15 & 13 & 0 & 0 & 0 & 15 \\
\hline 12 & KUR-12 & 8 & 0 & 16 & 14 & 12 & 23 & 21 \\
\hline 13 & PMR-13 & 0 & 0 & 0 & 13 & 0 & 9 & 0 \\
\hline 14 & PMR-14 & 0 & 0 & 0 & 0 & 0 & 0 & 0 \\
\hline 15 & PMR-15 & 0 & 0 & 0 & 0 & 0 & 0 & 0 \\
\hline 16 & PMR-16 & 0 & 15 & 14 & 0 & 0 & 0 & 12 \\
\hline 17 & PMR-17 & 21 & 0 & 0 & 12 & 8 & 7 & 11 \\
\hline 18 & PMR-18 & 19 & 14 & 16 & 20 & 12 & 16 & 0 \\
\hline 19 & PMR-19 & 0 & 12 & 15 & 0 & 0 & 0 & 0 \\
\hline 20 & PMR-20 & 0 & 0 & 0 & 0 & 0 & 0 & 12 \\
\hline 21 & PMR-21 & 8 & 11 & 11 & 12 & 9 & 10 & 8 \\
\hline 22 & PMR-22 & 0 & 0 & 0 & 12 & 15 & 23 & 11 \\
\hline 23 & VPR-23 & 9 & 0 & 0 & 12 & 16 & 14 & 13 \\
\hline 24 & VPR-24 & 14 & 0 & 0 & 13 & 0 & 0 & 11 \\
\hline 25 & VPR-25 & 19 & 0 & 0 & 0 & 0 & 0 & 9 \\
\hline 26 & VPR-26 & 11 & 0 & 0 & 10 & 0 & 13 & 0 \\
\hline 27 & VPR-27 & 12 & 0 & 0 & 0 & 21 & 14 & 14 \\
\hline 28 & VPR-28 & 0 & 0 & 0 & 0 & 0 & 0 & 12 \\
\hline 29 & VPR-29 & 9 & 15 & 16 & 0 & 0 & 11 & 0 \\
\hline 30 & VPR-30 & 0 & 0 & 0 & 0 & 0 & 0 & 10 \\
\hline 31 & JMR-31 & 14 & 0 & 0 & 13 & 8 & 7 & 14 \\
\hline 32 & JMR-32 & 0 & 0 & 0 & 18 & 9 & 10 & 0 \\
\hline 33 & JMR-33 & 12 & 13 & 9 & 0 & 0 & 8 & 0 \\
\hline 34 & JMR-34 & 22 & 18 & 19 & 21 & 20 & 11 & 9 \\
\hline 35 & JMR-35 & 15 & 0 & 10 & 16 & 9 & 14 & 0 \\
\hline 36 & JMR-36 & 9 & 0 & 0 & 12 & 16 & 14 & 13 \\
\hline
\end{tabular}

Note: EC-Escherichia coli, BS-Bacillus subtilis, SA-Staphylococcus aureus, PA-Pseudomonas aeruginosa,

PM-Proteus mirabilis, KP-Klebsiella pneumonia, CA-Candida albicans 
The forest soil samples collected from five different locations of Javadi hills upon inoculation on nutrient media yielded plenty of actinomycetes having different cultural and morphological characters. From among them thirty six actinomycetes strains were selected based on the colony morphology on starch casein agar and actinomycetes isolation agar medium. All of these collected strains were suspected to be actinomycetes since SCA medium supplemented with nalidixic acid $(20 \mathrm{mg} / \mathrm{ml})$ and nystatin $(100$ $\mathrm{mg} / \mathrm{ml}$ ) is a selective medium which inhibit the growth of other bacteria and fungi. Selective medium with nalidixic acid is found to be efficient for soil actinomycetes isolation and it is recommended for screening organisms producing new antibiotics[16]. Further this medium is very specific for the isolation of actinomycetes, as only organism (mostly actinomycetes) capable of degrading the polymers in the medium will be able to grow.

Five to ten colonies from each plate were selected based on colony appearance. Colonies having characteristic features such as powdery appearance with convex, concave or flat surface and color ranging from yellow, grey, brown, white, red and pinkish were selected. Colonies observed on $1^{\text {st }}$ and $2^{\text {nd }}$ day were eliminated because actinomycetes are considered as slow grower[17]. Furthermore, bacterial configuration same as actinomycetes were accepted from Gram staining. All the thirty six selected isolates were examined microscopically for their morphological characteristics and for their actinomycetes cultural characteristics (Table.1).

The bacterial antagonistic activities of all selected isolates determined against pathogenic bacteria by agar plug method and confirmation by cross streak method revealed the significant antibacterial and antifungal activities of most of the isolates (Table2). All the thirty six actinomycetes were screened for their antibacterial activity against five species of bacteria and one species of fungal pathogens. Antagonistic activities of actinobacterial isolates were tested by adopting agar plug method. Isolate BKM-4 showed antibacterial activities against four species of bacterial pathogens except Candida albicans. But PMR-18 strain showed antibacterial activities against both bacterial and fungal pathogens. Moreover six isolates BKM-1, BKM-4, BKM-7, KUR-8, KUR-12, PMR-17, JMR-34 and PMR-18 were found to have high activity against Escherichia coli, Pseudomonas aeruginosa, and Klebsiella pneumoniae tested for sensitivity. Ten different types of actinomycetes were found to have high antagonistic activity. Especially BKM-4 soil produces an intense antagonism. Among the screening methods used, agar plug, crowded plate, agar overlay, and cross streak used for the antagonistic activity detection, the agar plug method allowed utilization of very small amount of medium for both cultivation as well as bioactive compounds production besides antimicrobial activity detection of more number of actinomycetes against wide range of pathogens with less $\operatorname{cost}[14]$.

\section{Conclusions}

Considering the outcome of the present investigation, it was concluded that Javadhu hills is a rich source for deriving economically important Actinomyces. The antibiogram results indicated that the hill soils are source for hyperactive actinomycetes antagonistic against the pathogenic bacteria and fungi. The widest activity spectrum and the largest inhibition zones were shown by strains BKM-4, JMR-34 and PMR-18 while the first exhibited the best performance. Thus there is definite scope for bioprospecting of antagonistic actinomycetes from Javadi hill forest soil ecosystem once appropriate further studies are undertaken.

\section{REFERENCES}

[1] Paolina Garbeva, Olaf Tyc, Mitja N. P. Remus-Emsermann, Annemieke van der Wal, Michiel Vos, Mark Silby, Wietse de Boer, "No apparent costs for facultative antibiotic production by the soil bacterium Pseudomonas fluorescens Pf0-1", PLoS ONE, vol. 6, no.11, e27266, 2011.

[2] Oskay M, Tamer AU, Azeri C, "Antibacterial activity of some actinomycetes isolated from farming soils of Turkey", African Journal of Biotechnology, vol. 3, no.9, pp.441-446, 2004.

[3] Arifuzzaman M, Khatun MR, Rahman H, "Isolation and screening of actinomycetes from sundarabars soil for antibacterial activity" African Journal Of Biotechnology, vol 9, no 29, pp.4615-4619, 2010.

[4] Dinishi Jayasinghe BAT, Dennis Parkinson, “Actinomycetes as antagonists of litter decomposer fungi", Applied Soil Ecology, vol.38, no.2, pp.109- 118. 2008.

[5] Khaled A. El-Tarabily, Krishnapillai Sivasithamparam, "Non-streptomycete actinomycetes as biocontrol agents of soil-borne fungal plant pathogens and as plant growth promoters," Soil Biology and Biochemistry, vol.38, no.7, pp.1505-1520, 2006.

[6] Thangapandian V, Ponmurugan P, Ponmurugan K, "Actinomycetes diversity in the rhizosphere soils of different medicinal plants in Kolli Hills-Tamilnadu, India, for secondary metabolite production", Asian Journal of Plant Sciences, vol.6, no.1, pp.66-70. 2007.

[7] Panaiyadiyan P, Chellaia, SR, "Biodiversity of microorganisms isolated from rhizosphere soils of Pachamalai Hills, Tamilnadu, India," Research Journal of Forestry, vol. 5, no 1. pp. 27-35, 2011.

[8] Umasankar ME, Gaurav Kumar, Karthik L, Bhaskara Rao $\mathrm{KV}$, "Exploration of antagonistic actinobacteria from Amirthi forest," International Journal of Current Pharmaceutical Research, vol. 2, no.1, pp.16-19, 2010.

[9] Ismail Saadoun, Raad Gbaraibeh, "The streptomyces flora of bodia region of jorden and its potential as a source of antibiotics active against antibiotic-resistant bacteria," Journal of Arid Environment, vol.53, no.3, pp.365-371, 2003.

[10] Williams S, Shameemullah M, Watson E, Mayfield C, "Studies on the ecology of actinomycetes in soil. VI. The influ- 
ence of moisture tension on growth and survival", Soil biology and Biochemistry, vol. 4 no.2, pp.252-225, 1972.

[11] Valan Arasu M, Duraipandiyan V, Agastian P, Ignacimuthu S, "In vitro antimicrobial activity of Streptomyces spp. ERI-3 isolated from Western Ghats rock soil (India)", Journal de Mycologie Medicale, vol.19, no.1, pp.22-28, 2009

[12] Vernan S. Bernan, Deborah A. Montenegro, Joseph D. Korshalla, William M. Maiese, Deborah A. Steinberg, Michael Greenstein, "Bioxalomycins new antibiotics produced by the marine Streptomyces spp. LL-31F508: taxonomy and fermentation", Journal of Antibiotics, vol.47, no.12, pp.1417 $-24,1994$.

[13] Eccleston GP, Brooks PR, Kurtböke DI, "The occurrence of bioactive micromonosporae in aquatic habitats of the Sunshine Coast in Australia," Marine Drugs, vol.6, pp.243-261, 2008.
[14] Mohanraj, D, Bharathi S, M. Radhakrishnan M, Balagurunathan $\mathrm{R}$, "Bioprospecting of actinobacteria from Yelagiri hills with special reference to antibacterial activity," Journal of Chemical Pharmaceutical Research, vol. 3, no.3, pp.439-446, 2011.

[15] Coates ARM, Hu Y, "Novel approaches to developing new antibiotics for bacterial infections," British Journal of Pharmacology, vol. 152, no.8, pp.1147-1154, 2007.

[16] Alferova IV, Terekhova LP, Prauzer Kh, "Selective medium with nalidixic acid for isolating antibiotic-producing Actinomyces," Antibiotiki i khimioterapiia, vol.34, no.5, pp.344-8, 1989.

[17] Cameron R. Currie, Michael Poulsen, John Mendenhall, Jacobus J. Boomsma,Johan Billen,"Coevolved crypts and exocrine glands support mutualistic bacteria in fungus growing ants", Science vol.311, no.5757, pp.311:81-83, 2006. 